Article

\title{
Antioxidant Properties of Pyroligneous Acid Obtained by Thermochemical Conversion of Schisandra chinensis Baill
}

\section{Chunhui Ma ${ }^{1,2}$, Wei Li ${ }^{2}$, Yuangang Zu ${ }^{1}$, Lei Yang ${ }^{1, *}$ and Jian Li ${ }^{2, *}$}

1 State Engineering Laboratory for Bioresource Eco-Utilization, Northeast Forestry University, Harbin 150040, China; E-Mails: mchmchmchmch@163.com (C.M.); zygorl@163.com (Y.Z.)

2 College of Material Science and Engineering, Northeast Forestry University, Harbin 150040, China; E-Mail: liwei19820927@126.com

* Authors to whom correspondence should be addressed; E-Mails: ylmanefu@163.com (L.Y.); nefulijian@163.com (J.L.); Tel.: +86-451-8219-1387 (L.Y.); +86-451-8219-1517 (J.L.); Fax: +86-451-8210-2082 (L.Y. \& J.L.).

External Editor: Derek J. McPhee

Received: 13 October 2014; in revised form: 8 December 2014 / Accepted: 9 December 2014 / Published: 12 December 2014

\begin{abstract}
Sustainable development of renewable resources is a major challenge globally. Biomass is an important renewable energy source and an alternative to fossil fuels. Pyrolysis of biomass is a promising method for simultaneous production of biochar, bio-oil, pyroligneous acid (PA), and gaseous fuels. The purpose of this study was to investigate the pyrolysis process and products yields of Schisandra chinensis fruits with different pyrolysis powers. The obtained PA was extracted with organic solvents, including ethyl formate, dichloromethane, methanol and tetrahydrofuran. The antioxidant activities, including the free radical scavenging activity and ferric reducing power, of the PA extracts were investigated. The synthetic antioxidants butylated hydroxyanisole and butylated hydroxytoluene were used as positive controls. A dichloromethane extract of PA showed excellent antioxidant properties compared to the other extracts. The chemical compositions of the PA extracts were determined by GC-MS, and further proved that the dichloromethane extract had the best antioxidant characteristics among the extracts tested.
\end{abstract}

Keywords: Schisandra chinensis Baill.; pyrolysis; pyroligneous acid; antioxidant activity; GC-MS 


\section{Introduction}

Biomass is an important renewable resource, and its use for energy production provides economic security that is less environmentally damaging than that of other energy sources. Biomass can be converted by thermochemical processes, including pyrolysis, combustion, gasification, and liquefaction. Pyrolysis is an efficient method for utilization of biomass, especially for agricultural countries with large quantities of available biomass by-products [1,2]. The products of biomass pyrolysis include char, gas, tar and pyroligneous acid (PA).

Also known as wood vinegar or pyroligneous liquor, PA is a complex mixture of water, alcohols, organic acids, phenolics, aldehydes, ketones, esters, furan and pyran derivatives, hydrocarbons, and nitrogen compounds [3,4]. The composition and yield of PA depends on the species the biomass was derived from, and pyrolysis conditions. PA is a reddish-brown, acidic, water-soluble wood distillate, which is used in pesticides, refined food additives [5], and smoke flavoring [6]. PA is useful for soil improvement, and especially for the control of fungal and termite infestations [7,8]. PA also exhibits excellent antioxidant activity. PA from bamboo has superoxide anion scavenging activity and antioxidant activity [9]. Antioxidant and free radical scavenging activities have been reported for PAs from Rhizophora apiculata [10], walnut shells [11], and hickory shells [12]. PA has potential as a natural antioxidant because it is rich in phenolic compounds and can be used as a food antioxidant [11].

Antioxidants have become important because of their role in health and their effects on cardiovascular disease, atherosclerosis, cancer, and aging. Many antioxidant compounds from plant sources have been identified as free radical scavengers $[13,14]$. In recent years, the search for naturally occurring antioxidants for use in food and medicine has intensified in order to replace synthetic antioxidants $[15,16]$, which are being restricted because of their side effects (e.g., carcinogenicity) [17]. A number of synthetic antioxidants, such as 2-tert-butyl-4-methoxyphenol and 3-tert-butyl-4-methoxyphenol (butylated hydroxyanisole, BHA), and tert-butylhydroquinone are added to foodstuffs, but their use has come under scrutiny because of toxicity issues [18]. Therefore, attention has been directed towards the discovery of natural antioxidants from plant sources. Crude extracts of plant materials rich in polyphenols are increasingly of interest to the food industry because of their capacity to retard oxidative degradation of lipids and thereby improve the quality and nutritional value of food [13].

The composition and yield of PA depends on the pyrolysis process conditions and the biomass raw materials. Extensive studies of the chemical compositions and applications of PAs from oak, sakura, green tea, bamboo, eucalyptus, mangrove, rosemary and waste biomass have been conducted [7,10,19]. However, the themochemical conversion of Schisandra chinensis Baill. (S. chinensis) and chemical composition and antioxidant activity of $S$. chinensis PA have not been studied in detail.

Dried fruit of $S$. chinensis are important in herbal medicines and as a food additive in China [20]. They are used extensively in Korea and Japan as a tonic, sedative and astringent agent to treat various diseases [21-23]. Modern pharmacological research has shown that S. chinensis has antioxidant, antitumor [24], anti-hepatotoxic, detoxificant, anticarcinogenic [25], and anti-inflammatory [26] activity, and can act on the central nervous system. In addition, it can reduce fatigue and increase endurance, which can contribute to improved physical performance in sports [27]. In China, it is also used as a flavor agent and food additive when stewing fish and meat and making soup, tea, yogurt and porridge [28-31]. The chemical composition of $S$. chinensis fruits includes essential oil terpenoids [32], 
polysaccharides [33], anthocyanins [34], organic acids, vitamins, tannins [35], and biphenyl cyclooctene lignans [36] was shown in Table 1.

Table 1. Chemical composition of $S$. chinensis fruits.

\begin{tabular}{ccc}
\hline Chemical Composition & Content (\%) & Reference \\
\hline Essential oil & $1.2-3.0$ & {$[32]$} \\
Polysaccharides & $1.2-2.2$ & {$[33]$} \\
Anthocyanins & $2.0-3.2$ & {$[34]$} \\
Terpenoids & $<1.5$ & {$[35]$} \\
Organic acids (citric, malic, fumaric and tartaric acid) & $<1.0$ & {$[35]$} \\
Vitamins C and E & $<0.5$ & {$[35]$} \\
Tannins & $<1.5$ & {$[35]$} \\
Biphenyl cyclooctene lignans and derivatives & $7.2-19.2$ & {$[36]$} \\
\hline
\end{tabular}

This study aimed to investigate the pyrolysis of $S$. chinensis, which can be used to obtained the natural antioxidant $S$. chinensis PA and to reduce environmental pollution from fossil fuels. Another objective of this study was to evaluate the phenolic content, radical scavenging activity, and reducing power of S. chinensis PA extracts in ethyl formate, dichloromethane, methanol, and tetrahydrofuran. The extracts were obtained after pyrolysis under different heating conditions. The results could be used for development of antioxidants and preservatives from S. chinensis PA.

\section{Results and Discussion}

\subsection{Influence of Moisture Content and Molding Temperature on the Briquetting Effect}

Dried residues with different moisture contents $(3.5 \%, 4.0 \%, 5.0 \%, 5.5 \%, 6.5 \%, 8.0 \%, 9.5 \%$, $10.5 \%, 11.5 \%, 13.0 \%, 14.0 \%, 15.5 \%, 16.0 \%, 17.5 \%)$ were put into the hopper, respectively, and then the electric heating tube was opened, the molding temperature was kept at $200{ }^{\circ} \mathrm{C}$, and the extrusion machine was started, driving the spiral propellers to push the dried residues into the molding sleeve. The briquetting effect of molding rods is shown in Table 2 . When the residual moisture was less than $5 \%$ or more than $15 \%$, it cannot be briquetted. While the residual moisture was $5 \%-8 \%$ or $13 \%-15 \%$, the molding effect was poor, although it can be briquetted. However, when the residual moisture was $8 \%-13 \%$, the briquetted effect of molding rods was good, so the ideal residual moisture for the briquette production process was $8 \%-13 \%$.

Table 2. Effect of moisture content on raw residue briquetting.

\begin{tabular}{cccccc}
\hline Moisture (\%) & $<5 \%$ & $5 \%-8 \%$ & $8 \%-13 \%$ & $13 \%-15 \%$ & $>15 \%$ \\
\hline Can be Briquetted & No & Almost not & Yes & Almost not & No \\
\hline
\end{tabular}

Dried residue with $10.0 \%$ moisture content was put into the hopper, and then the electric heating tube was opened, and the molding temperature were kept at different temperatures $(50,100,150,200,250$, 300,350 and $400{ }^{\circ} \mathrm{C}$ ), respectively, and the extrusion machine was started, driving the spiral propellers to push the dried residues into the molding sleeve. The briquetting effect of molding rods is shown in Table 3. When the molding temperature was less than $150{ }^{\circ} \mathrm{C}$ or more than $400{ }^{\circ} \mathrm{C}$, it cannot be 
briquetted. When the molding temperature was $250-400{ }^{\circ} \mathrm{C}$ the briquetting effect is poor, and there were some cracks on the molding rods' surface. When the molding temperature was $200{ }^{\circ} \mathrm{C}$, the briquetting effect of the molding rods was good, there were no cracks and they were not carbonized on surface, and the molding rods output speed was the most fast of all.

Table 3. Effect of temperature on raw residue briquetting.

\begin{tabular}{ccccccccc}
\hline Briquetting Temperature $\left({ }^{\circ} \mathbf{C}\right)$ & $\mathbf{5 0}$ & $\mathbf{1 0 0}$ & $\mathbf{1 5 0}$ & $\mathbf{2 0 0}$ & $\mathbf{2 5 0}$ & $\mathbf{3 0 0}$ & $\mathbf{3 5 0}$ & $\mathbf{4 0 0}$ \\
\hline Can be briquetted & No & No & Yes & Yes & Yes & Yes & Almost not & No \\
Cracks on surface & & & Yes & No & Yes & Yes & A lot & - \\
Carbonized on surface & - & - & No & No & A little & Partial & Totally & Seriously \\
Briquetting rate $(\mathrm{kg} / \mathrm{min})$ & - & - & 2.1 & 2.0 & 1.8 & 1.8 & 1.7 & - \\
\hline
\end{tabular}

\subsection{Pyrolysis Curves and Yields of Pyrolysis Products}

The pyrolysis curves shows the pyrolysis temperature against pyrolysis time. The yields of the pyrolysis products, including bio-gas, bio-PA, bio-oil, and bio-char, are shown in Figure 1. The pyrolysis curves (Figure 1a) showed that with a higher heating power, the temperature increased more rapidly and the pyrolysis rate was higher.

Figure 1. Pyrolysis curves (a) and the yields of pyrolysis products (b) generated with different heating powers.
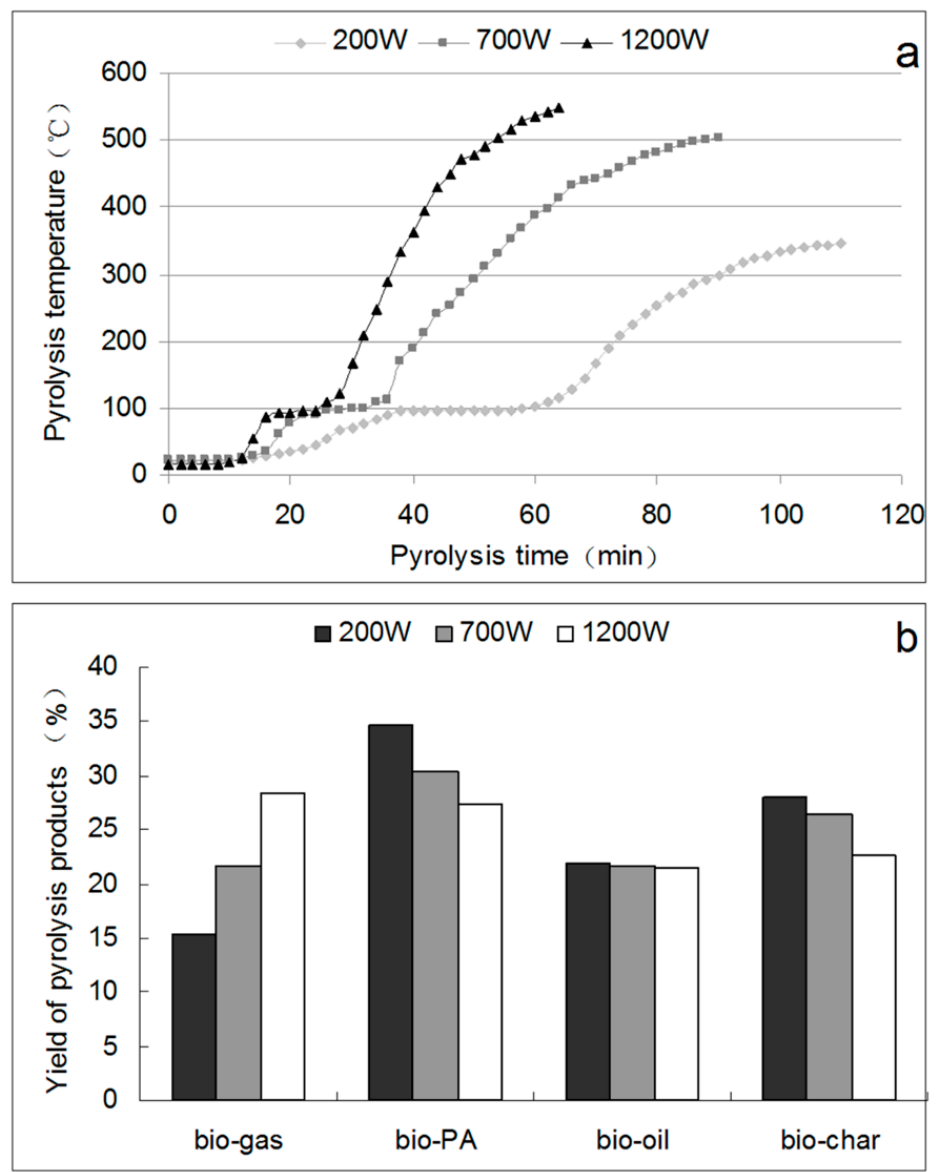
The maximum final temperature of the pyrolysis reaction was close to $600{ }^{\circ} \mathrm{C}(1200 \mathrm{~W})$. Depending on the thermal environment and the final temperature, pyrolysis will yield mainly biochar at low temperatures $\left(<450{ }^{\circ} \mathrm{C}\right)$ when the heating rate is quite slow, and mainly gases at high temperatures $\left(>800{ }^{\circ} \mathrm{C}\right)$ with rapid heating rates. At an intermediate temperature and under relatively high heating rates, the main product is bio-oil. From Figure $1 \mathrm{~b}$, the yields of bio-oil pyrolysis with different powers were similar, and the yields of bio-oil were $21.5 \%(200 \mathrm{~W}), 21.4 \%(700 \mathrm{~W})$, and $21.4 \%(1200 \mathrm{~W})$, respectively, of the total pyrolysis products. However, when the pyrolysis power increased, the bio-gas yield increased and the bio-PA and bio-char yields decreased, the PA yield with $200 \mathrm{~W}$ pyrolysis was $34.5 \%$ of the total pyrolysis products, more than that with pyrolysis at higher power $30.4 \%(700 \mathrm{~W})$, and $27.5 \%(1200 \mathrm{~W})$, respectively. The char yield with $200 \mathrm{~W}$ pyrolysis was $28.4 \%$ of the total pyrolysis products, more than that with pyrolysis at higher power $26.1 \%(700 \mathrm{~W})$, and $22.5 \%(1200 \mathrm{~W})$, respectively. Thus, to obtain high yields of bio-PA and bio-char, a low power pyrolysis (200 W) should be used. The mass difference from input and output products was determined by the product mass of non-condensable gas. The bio-gas yields were 15.6\% (200 W), 22.1\% (700 W), and 28.6\% $(1200 \mathrm{~W})$ of the total pyrolysis products, respectively. Therefore, the higher the pyrolysis power, the faster the pyrolysis rate was, and the larger the amount of non-condensable gas produced was.

\subsection{Separation of PA from Bio-Oil}

The condensate collected from the condenser was a mixture of PA and bio-oil, and separation by cooling was a simple way to separate the bio-PA (the upper layer) from the bio-oil (the lower layer). To investigate the effect of the separation temperature on separation time, five $200 \mathrm{~mL}$ aliquots of condensate were accurately measured and then poured into a separatory funnel, cooled at different temperatures $\left(-5^{\circ} \mathrm{C}-20^{\circ} \mathrm{C}\right)$. The volume of PA and bio-oil were recorded every hour, and the separation time was recorded at the time at which the volumes stopped changing. The separation curve for PA and bio-oil is shown in Figure 2.

Figure 2. Effect of temperature on time required to separate bio-PA and bio-oil.

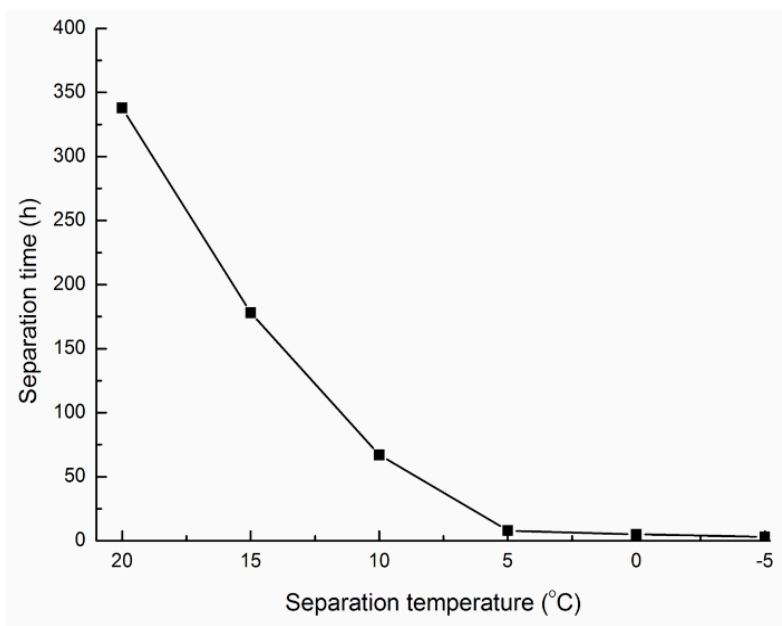

Lower cooling temperatures gave better separation of the two phases than higher temperatures, and this reduced the separation time. Separation of the condensate at $20{ }^{\circ} \mathrm{C}$ required nearly $350 \mathrm{~h}$ for complete separation. The separation rate was higher below $5{ }^{\circ} \mathrm{C}$, and the condensate was completely 
separated within $12 \mathrm{~h}$. If the condensate was separated at a temperature below $0{ }^{\circ} \mathrm{C}$, it would need refrigeration, which would increase energy consumption. Therefore, $5{ }^{\circ} \mathrm{C}$ was selected as the operation temperature to separate bio-PA from bio-oil. After stratification in the closed separatory funnel, the bio-oil (the lower layer) was removed and the antioxidant capacities of the bio-PA was determined.

\subsection{Determination of Total Phenolics Content}

The Folin-Ciocalteu assay is a fast and simple method to rapidly determine the content of phenolics in samples. Most of the work dealing with the content of phenolics in natural products uses gallic acid as a standard, and the content of phenolics in this work is expressed as gallic acid equivalents to facilitate comparison to earlier studies [37]. As shown in Table 4, the total phenolic content of PA-200 (pyrolysis at $200 \mathrm{~W}$ ) was higher than that of PA-700 (pyrolysis at $700 \mathrm{~W}$ ) and PA-1200 (pyrolysis at $1200 \mathrm{~W}$ ), because the phenolic compounds were not destroyed (i.e., pyrolyzed) under the low temperature conditions. Furthermore, some of the water-soluble phenolic compounds were extracted into water under the lower temperature conditions, because of slow evaporation of moisture from the residue. Consequently, the total phenolic content of PA-200 was the highest, and PA-200 was selected for the antioxidant activity tests. As shown in Table 4, in all the PA extracts, the total phenolic contents of DMEP and MEP were higher than those of EFEP and TFEP. This means the phenolic compounds in PA were more likely to be soluble in dichloromethane and methanol.

Table 4. Total phenolic content of PA extracts.

\begin{tabular}{cccccc}
\hline \multirow{2}{*}{$\begin{array}{c}\text { Heating Power } \\
(\mathbf{W})\end{array}$} & \multirow{2}{*}{ Symbols } & \multicolumn{4}{c}{ Gallic Acid Equivalents (mg/g) } \\
\cline { 3 - 6 } & & EFEP $^{\text {a }}$ & DMEP $^{\text {b }}$ & MEP $^{\mathbf{c}}$ & TFEP $^{\text {d }}$ \\
\hline 200 & PA-200 & $2.36 \pm 0.05$ & $3.91 \pm 0.13$ & $3.79 \pm 0.14$ & $2.14 \pm 0.10$ \\
700 & PA-700 & $2.35 \pm 0.12$ & $3.79 \pm 0.11$ & $3.47 \pm 0.15$ & $1.99 \pm 0.06$ \\
1200 & PA-1200 & $2.30 \pm 0.13$ & $2.81 \pm 0.14$ & $2.69 \pm 0.10$ & $1.58 \pm 0.08$ \\
\hline
\end{tabular}

a EFEP: ethyl formate extract phase of pyroligneous acid; ${ }^{b}$ DMEP: dichloromethane extract phase of pyroligneous acid; ${ }^{c}$ MEP: methanol extract phase of pyroligneous acid; ${ }^{d}$ TFEP: tetrahydrofuran extract phase of pyroligneous acid.

\subsection{Ferric Reducing Power}

The antioxidant potentials of the PA extracts were estimated from their ability to reduce TPTZ-Fe(III) to TPTZ-Fe(II) [38]. A higher absorbance indicated a higher ferric reducing power. The reducing antioxidant power of each sample is expressed as Trolox equivalents, and the reducing antioxidant power of solvent was deducted as a blank. Figure 3 shows the reduction capacities of the various extracts from samples subjected to different heating powers during pyrolysis. Figure 3a (PA-200) shows that the reduction capacities of MEP and DMEP at $100 \mu \mathrm{g} / \mathrm{mL}$ were $587.55 \pm 22.50$ and $522.05 \pm 32.20(\mathrm{TE}) / \mathrm{g}$, respectively. These results were higher than those of EFEP $(102.35 \pm 4.20(\mathrm{TE}) / \mathrm{g})$ and TFEP $(148.05 \pm 8.43(\mathrm{TE}) / \mathrm{g})$ at the same concentration. The reduction capacities of BHA and $\mathrm{BHT}$ at $100 \mu \mathrm{g} / \mathrm{mL}$ were $344.05 \pm 11.11(\mathrm{TE}) / \mathrm{g}$ and $94.35 \pm 2.34(\mathrm{TE}) / \mathrm{g}$, respectively. Figure $3 \mathrm{~b}$ (PA-700) and Figure 3c (PA-1200) show the same trends. The reducing power order of PA-200 was 
MEP $>$ DMEP $>$ BHA $>$ TFEP $>$ EFEP $>$ BHT, while the order of PA-700 was MEP $>$ BHA $>$ DMEP $>$ BHT $>$ TFEP $>$ EFEP, and the order of PA-1200 was BHA $>$ MEP $>$ DMEP $>$ BHT $>$ TFEP $>$ EFEP.

Figure 3. Reducing antioxidant capacities of PA extracts after (a) pyrolysis at $200 \mathrm{~W}$; (b) pyrolysis at $700 \mathrm{~W}$; (c) pyrolysis at $1200 \mathrm{~W}$.
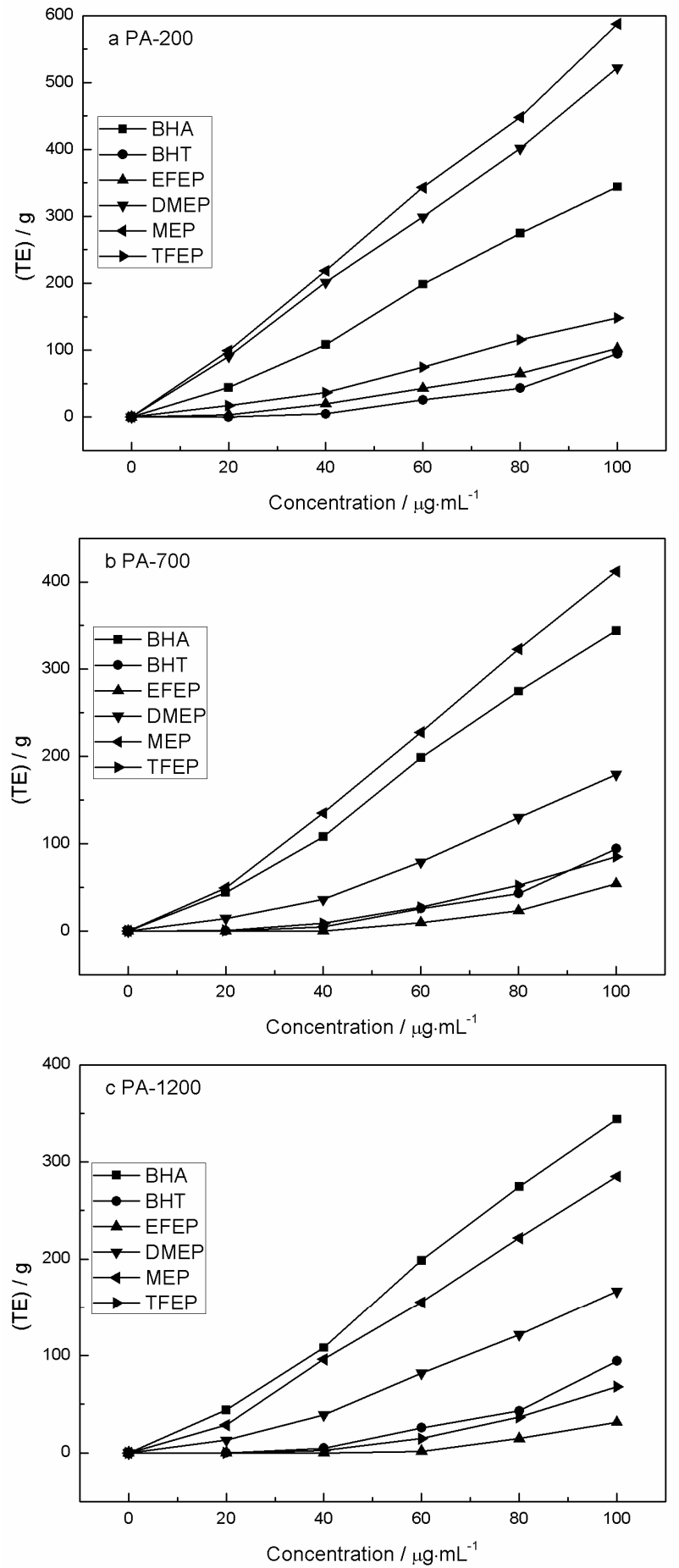

\subsection{DPPH Free Radical Scavenging Activity}

DPPH is a stable free radical, and can accept an electron or hydrogen free radical to reach a steady state [39]. Consequently, DPPH has been widely used to determine the free-radical scavenging abilities 
of various samples. When the scavenging rate of DPPH is $50 \%$, the corresponding value of sample concentration is SC50. So, a lower SC50 value indicates the stronger antioxidant activity. As shown in Figure 4, an obvious increase in SC\% value occurred when the concentration of PA increased.

Figure 4. DPPH scavenging activities of PA extracts after (a) pyrolysis at $200 \mathrm{~W}$; (b) pyrolysis at $700 \mathrm{~W}$; (c) pyrolysis at $1200 \mathrm{~W}$.
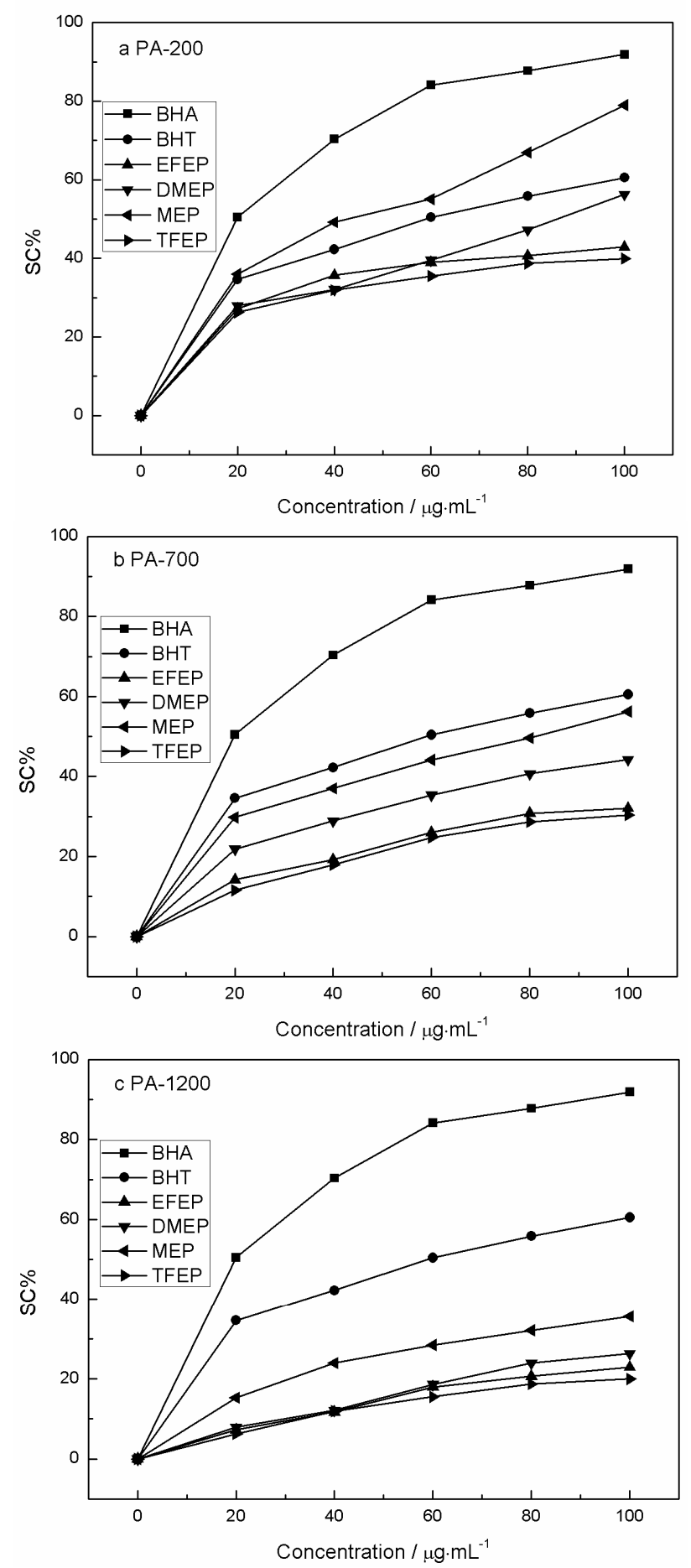

Thus, the DPPH scavenging activities decreased order was MEP $>$ DMEP $>$ EFEP $>$ TFEP. The DPPH scavenging activity of PA-200 (Figure 4a) was higher than that of PA-700 (Figure 4b) and PA-1200 (Figure 4c), as the lower heating power enhance the residence time of liquid pyrolysis 
products, increasing the content of water soluble bioactive small molecules [10]. In detail, the yields of pyrolysis products, such as the condenser and bio-char depend on the heating rate of pyrolysis. In other words, the lower heating power and the slower pyrolysis rate, the pyrolysis reaction is more completely, and the yield of the condenser liquid is higher. And vice the higher heating power and faster pyrolysis, enhance the solid pyrolysis products thus increasing bio-char formation [2]. When the pyrolysis power was $200 \mathrm{~W}$, the SC50 values of MEP and DMEP were $41 \pm 1.2$ and $92 \pm 2.3 \mu \mathrm{g} / \mathrm{mL}$, respectively, and were lower than the SC50 values of EFEP and TFEP. The SC50 values of BHA and BHT were $19 \pm 0.23$ and $60 \pm 0.30 \mu \mathrm{g} / \mathrm{mL}$, respectively. The DPPH scavenging activities of PA-200 were in the order BHA $>$ MEP $>$ BHT $>$ DMEP $>$ EFEP $>$ TFEP. While for PA-700 and PA-1200, the order was BHA $>$ BHT $>$ MEP $>$ DMEP $>$ EFEP $>$ TFEP.

\subsection{Chemical Composition of PA Extracts}

The compositions of the $S$. chinensis PA extracts were analyzed by GC-MS. Results were accepted when a match $>90 \%$ was obtained. The relative contents of the compounds were determined using the normalization method. Among the pyrolysis powers tested, $200 \mathrm{~W}$ pyrolysis gave the highest yield of PA, and PA-200 had the highest total phenolic content. Therefore, we used PA-200 for the antioxidant test, and extracted it with four different organic solvents. The GC-MS results from this study are shown in Table 5.

Table 5. Volatile compounds in PA-200 extracts.

\begin{tabular}{|c|c|c|c|c|c|c|c|c|}
\hline \multirow{2}{*}{ No. } & \multirow{2}{*}{$\begin{array}{l}\text { Retention } \\
\text { Time(min) }\end{array}$} & \multirow{2}{*}{ Compounds } & \multirow{2}{*}{ CAS Number } & \multirow{2}{*}{$\begin{array}{c}\text { Molecular } \\
\text { Formula }\end{array}$} & \multicolumn{4}{|c|}{ RA\% ${ }^{a}$} \\
\hline & & & & & EFEP b & DMEP c & MEP d & TFEP $^{\mathrm{e}}$ \\
\hline 1 & 5.498 & Pyridine, 3,4-dimethyl- & $000583-58-4$ & $\mathrm{C}_{7} \mathrm{H}_{9} \mathrm{~N}$ & - & - & - & 9.07 \\
\hline 2 & 6.106 & $\begin{array}{c}\text { 2,5-Furandione, } \\
\text { 3-methyl- }\end{array}$ & 000616-02-4 & $\mathrm{C}_{5} \mathrm{H}_{4} \mathrm{O}_{3}$ & 16.43 & 7.20 & 17.06 & 14.35 \\
\hline 3 & 6.489 & $\begin{array}{l}\text { 2-Cyclopenten-1-one, } \\
\text { 3-methyl- }\end{array}$ & $002758-18-1$ & $\mathrm{C}_{6} \mathrm{H}_{8} \mathrm{O}$ & 4.89 & 6.87 & - & 2.82 \\
\hline 4 & 7.078 & Formic acid phenyl ester & 001864-94-4 & $\mathrm{C}_{7} \mathrm{H}_{6} \mathrm{O}_{2}$ & 19.88 & 20.89 & 17.80 & 18.39 \\
\hline 5 & 8.065 & $\begin{array}{l}\text { 1,2-Cyclopentanedione, } \\
\text { 3-methyl- }\end{array}$ & $000765-70-8$ & $\mathrm{C}_{6} \mathrm{H}_{8} \mathrm{O}_{2}$ & 2.50 & - & - & - \\
\hline 6 & 8.686 & Ethylidenecyclobutane & $001528-21-8$ & $\mathrm{C}_{6} \mathrm{H}_{10}$ & 1.70 & 3.15 & - & 1.79 \\
\hline 7 & 9.261 & p-Cresol & $000106-44-5$ & $\mathrm{C}_{7} \mathrm{H}_{8} \mathrm{O}$ & 10.41 & 16.24 & 22.84 & 10.35 \\
\hline 8 & 9.429 & $\begin{array}{l}\text { Phosphonofluoridic acid, } \\
\text { ethyl-, nonyl ester }\end{array}$ & $171741-07-4$ & $\mathrm{C}_{11} \mathrm{H}_{24} \mathrm{FO}_{2} \mathrm{P}$ & 9.57 & 12.51 & 9.50 & 8.85 \\
\hline & & $2,4(1 \mathrm{H}, 3 \mathrm{H})-$ & & & & & & \\
\hline 9 & 9.755 & Pyrimidinedione, & $000932-52-5$ & $\mathrm{C}_{4} \mathrm{H}_{5} \mathrm{~N}_{3} \mathrm{O}_{2}$ & 9.98 & 12.61 & 9.29 & 9.07 \\
\hline 10 & 9.929 & $\begin{array}{c}\text { 5-amino- } \\
\text { 4-Piperidinone, } \\
\text { 2,2,6,6-tetramethyl- }\end{array}$ & 000826-36-8 & $\mathrm{C}_{9} \mathrm{H}_{17} \mathrm{NO}$ & 2.41 & 3.74 & 1.87 & 2.29 \\
\hline 11 & 9.996 & 1-Hexene, 2-methyl- & 006094-02-6 & $\mathrm{C}_{7} \mathrm{H}_{14}$ & 0.71 & - & 2.38 & - \\
\hline 12 & 10.243 & $\begin{array}{l}\text { 2,5-Pyrrolidinedione, } \\
\text { 1-ethyl- }\end{array}$ & $002314-78-5$ & $\mathrm{C}_{6} \mathrm{H}_{9} \mathrm{NO}_{2}$ & 1.21 & - & 2.59 & - \\
\hline
\end{tabular}


Table 5. Cont.

\begin{tabular}{|c|c|c|c|c|c|c|c|c|}
\hline \multirow{2}{*}{ No. } & \multirow{2}{*}{$\begin{array}{l}\text { Retention } \\
\text { Time(min) }\end{array}$} & \multirow{2}{*}{ Compounds } & \multirow{2}{*}{ CAS Number } & \multirow{2}{*}{$\begin{array}{c}\text { Molecular } \\
\text { Formula }\end{array}$} & \multicolumn{4}{|c|}{$\mathbf{R A} \%^{\text {a }}$} \\
\hline & & & & & EFEP ${ }^{b}$ & DMEP $^{\text {c }}$ & MEP $^{d}$ & TFEP $^{\mathrm{e}}$ \\
\hline 13 & 10.294 & 4-Pyridinol & $000626-64-2$ & $\mathrm{C}_{5} \mathrm{H}_{5} \mathrm{NO}$ & 1.66 & - & 2.83 & - \\
\hline 14 & 10.510 & Succinimide & 000123-56-8 & $\mathrm{C}_{4} \mathrm{H}_{5} \mathrm{NO}_{2}$ & 2.03 & 7.71 & - & 2.87 \\
\hline 15 & 10.698 & Glutarimide & 001121-89-7 & $\mathrm{C}_{5} \mathrm{H}_{7} \mathrm{NO}_{2}$ & 3.60 & - & 6.04 & 3.73 \\
\hline 16 & 10.869 & 4,5,6-Pyrimidinetriamine & 000118-70-7 & $\mathrm{C}_{4} \mathrm{H}_{7} \mathrm{~N}_{5}$ & 2.23 & 2.65 & - & 3.68 \\
\hline 17 & 10.926 & $\begin{array}{l}\text { 3,3-Dimethylpyrrolidine- } \\
\text { 2,5-dione }\end{array}$ & $003437-29-4$ & $\mathrm{C}_{6} \mathrm{H}_{9} \mathrm{NO}_{2}$ & 1.56 & - & - & 3.27 \\
\hline 18 & 11.261 & Creosol & $000093-51-6$ & $\mathrm{C}_{8} \mathrm{H}_{10} \mathrm{O}_{2}$ & 1.24 & - & - & 1.95 \\
\hline 19 & 11.490 & $\begin{array}{l}\text { 3-Pyridinol, 2,6- } \\
\text { dimethyl- }\end{array}$ & $001122-43-6$ & $\mathrm{C}_{7} \mathrm{H}_{9} \mathrm{NO}$ & - & $\longrightarrow$ & - & 0.54 \\
\hline 20 & 11.655 & $\begin{array}{c}\text { 1,4,3,6-Dianhydro-alpha- } \\
\text { d-glucopyranose }\end{array}$ & $100009-81-8$ & $\mathrm{C}_{6} \mathrm{H}_{8} \mathrm{O}_{4}$ & 5.01 & 3.51 & - & 2.09 \\
\hline 21 & 13.578 & Hydroquinone & 000123-31-9 & $\mathrm{C}_{6} \mathrm{H}_{6} \mathrm{O}_{2}$ & - & - & 5.75 & - \\
\hline $22^{\mathrm{f}}$ & 33.801 & $\begin{array}{c}\text { Phenol,2,2'- } \\
\text { methylenebis[6-(1,1- } \\
\text { dimethylethyl)-4-methyl- }\end{array}$ & 000119-47-1 & $\mathrm{C}_{23} \mathrm{H}_{32} \mathrm{O}_{2}$ & 2.98 & 2.92 & 2.05 & 4.89 \\
\hline
\end{tabular}

${ }^{a}$ RA: relative area of total peak area (removed the blank solvent); ${ }^{b}$ EFEP: ethyl formate extract phase of pyroligneous acid; ${ }^{c}$ DMEP: dichloromethane extract phase of pyroligneous acid; ${ }^{d}$ MEP: methanol extract phase of pyroligneous acid; ${ }^{\text {e }}$ TFEP: tetrahydrofuran extract phase of pyroligneous acid; ${ }^{\mathrm{f}}$ Compound No. 22: Butylated hydroxytoluene (BHT) is added in the solvent to keep the stability of solvent, is not the composition of PA.

According to previous studies, the thermal degradation characteristics of wood materials or plants are strongly influenced by their chemical composition (cellulose, hemicellulose, and lignin) [40-42]. Biomass undergoing pyrolytic reactions at high temperatures forms different compounds. Saccharides, including cellulose, hemicellulose and pectin, are thermally degraded into ketones, alcohols, and furan and pyran derivatives. However, lignin is converted into phenol, guaiacol, syringol, pyrocatechol, and their derivatives, which are dissolved in the bio-oil layer [39]. After cryogenic separation, smaller molecules partition into the water layer (i.e., the PA layer) and larger molecules in the bio-oil layer. The gas chromatograms and the main constituents of MEP are shown in Figure 5.

Figure 5. Total ion chromatogram and the main constituents of PA-200 MEP.

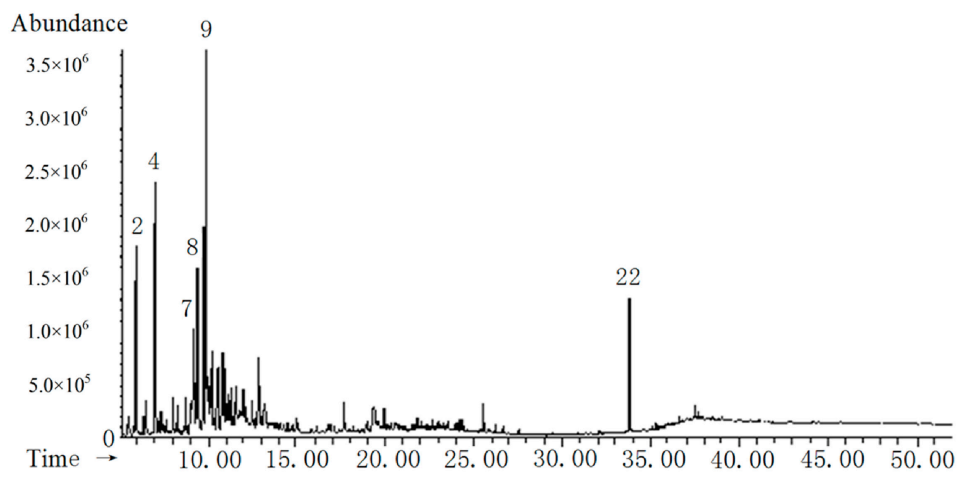


Figure 5. Cont.
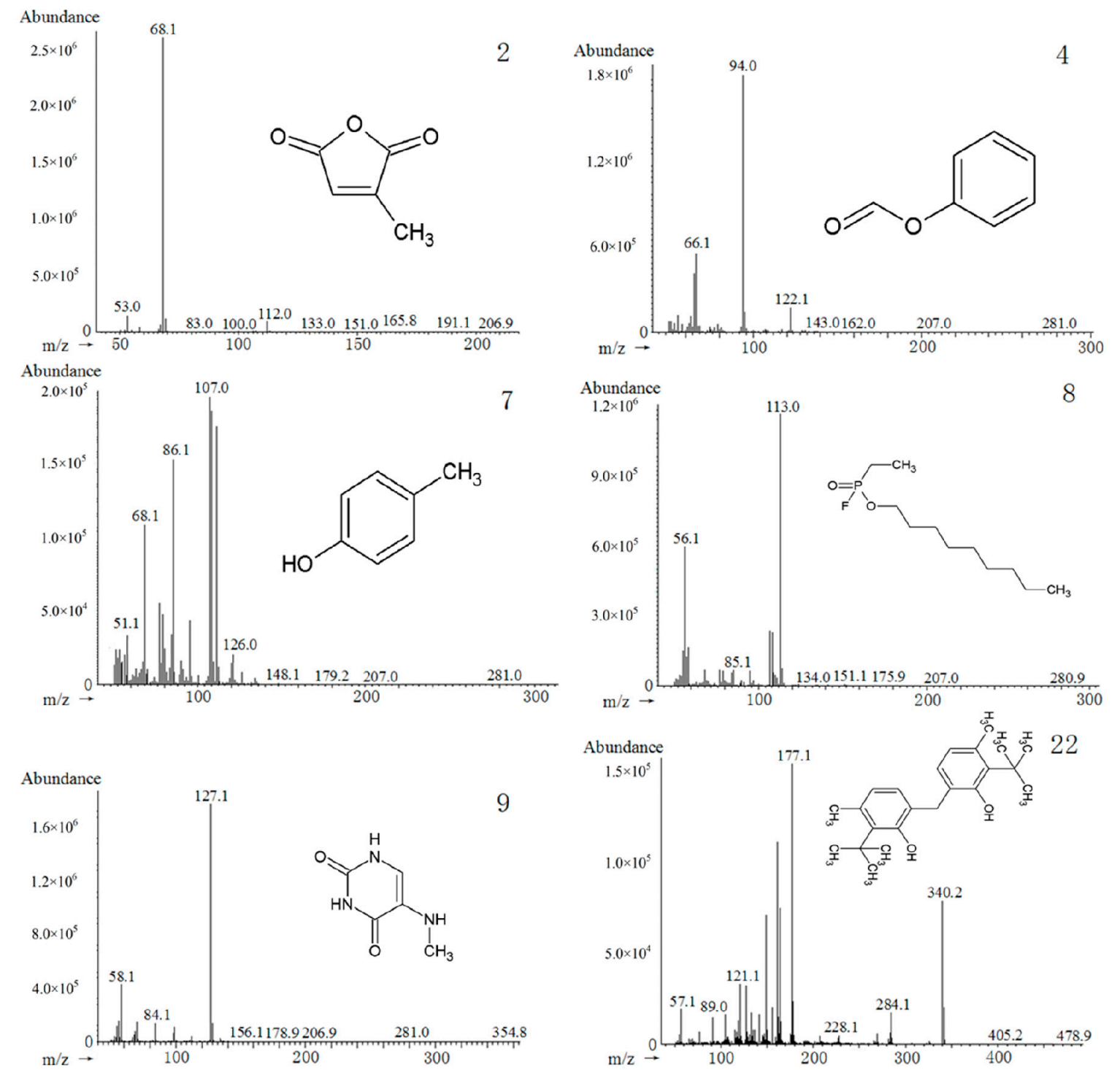

The compound numbers in Figure 5 correspond to those in Table 5. The main constituents of MEP were $p$-cresol $(22.84 \%)$, formic acid phenyl ester $(17.80 \%)$, and furandione $(17.06 \%)$. The main constituents of DMEP were $p$-cresol (16.24\%), formic acid phenyl ester $(20.89 \%)$, and furandione (7.20\%). However, which in EFEP and TFEP was slightly lower, and the antioxidant activity of MEP and DMEP was higher than that of EFEP and TFEP. Therefore, in combination with the results of total phenolics content, ferric reducing power, and free radical scavenging activity, the phenolic hydroxyl and polyenes played an important role in improving the oxidative resistance of PA after pyrolysis. Twelve compounds from DMEP and MEP were identified, and for EFEP and TFEP, 19 and 17 compounds were identified, respectively. BHT (No. 22 compounds), which was added to the solvent to maintain its stability, was present in small amounts $(<5.0 \%)$.

These results indicate that compounds containing the phenolic hydroxyl group are functional components responsible for the reduction of oxidants and scavenging of free radicals. This conclusion is supported by similar results obtained in other studies $[15,39]$. 


\section{Experimental Section}

\subsection{Material}

\subsubsection{Chemical Reagents}

Folin-Ciocalteu's reagent, 1,1-diphenyl-1-picrylhydrazyl (DPPH, 95\%), gallic acid, 2,4,6-tripyridylS-trizine (TPTZ), 6-hydroxy-2,5,7,8-tetramethylchromane-2-carboxylic acid (Trolox), butylated hydroxyanisole and butylated hydroxytoluene (BHT) were purchased from Sigma-Aldrich (St. Louis, MO, USA). All other chemicals of analytical grade and were obtained from Sinopharm Chemical Reagent Co., Ltd (Beijing, China). Reverse osmosis Milli-Q water (Millipore, Billerica, MA, USA) was used for all solutions and dilutions.

\subsubsection{Raw Materials}

S. chinensis fruit were purchased from San Keshu Trading (Heilongjiang, China) and identified by Professor Shao-quan Nie from the Key Laboratory of Forest Plant Ecology, Northeast Forestry University (Harbin, China). S. chinensis fruit were crushed and refluxed twice with an ethanol-water $(80: 20, \mathrm{v} / \mathrm{v})$ solution at $90{ }^{\circ} \mathrm{C}$ for $2 \mathrm{~h}$ to obtain the active compounds, such as polysaccharides, anthocyanins, terpenoids, organic acids, vitamins, tannins, biphenyl cyclooctene lignans and derivatives, etc. And then the extracts were concentrated under the vacuum conditions, and the residues were stored under $-4^{\circ} \mathrm{C}$ until used for thermochemical conversion.

\subsection{Methods}

\subsubsection{Molding Method}

The dried residues prepared in Section 3.1.2 were dried and then compact molding in briquetting equipment. In the process of compact molding, there is continuous feeding and continuous discharge mode with the improved briquetting equipment. The dried residual were first put into the hopper, and then the electric heating tube and the extrusion machine were started, driving the spiral propellers put the dried residual into the molding sleeve. Finally, the molding rods were export from the exit of molding sleeve. The schematic diagram of briquetting equipment was shown in Figure 6.

Figure 6. Schematic diagram of the briquetting equipment.

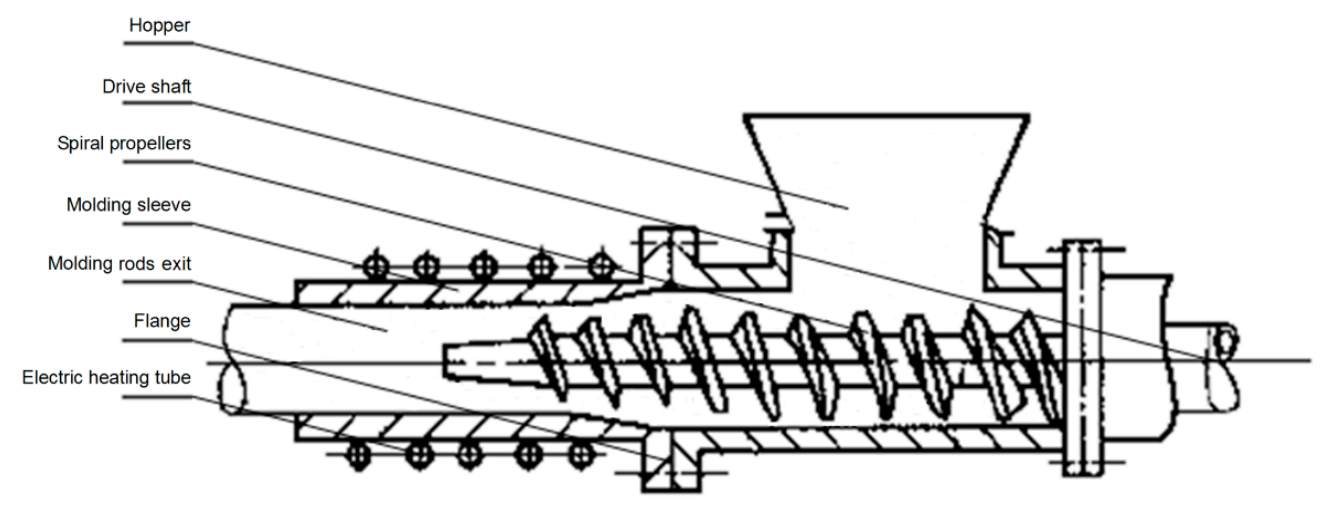




\subsubsection{Pyrolysis Method}

The molding rods prepared in Section 3.2.1 was heated for pyrolysis in a system consisting of a pyrolysis kettle and condensers (Figure 7). The molding rods were placed in the pyrolysis kettle, and the liquefier and pyrolysis kettle were started. The pyrolysis rate was controlled by adjusting the heating power, and the condensate was collected and the residual tar was purified. Then, the electric heating tube was opened. The end point of the pyrolytic reaction was determined by weighing the transducer. At the end point, the final weight increase of the condensate was less than $2.0 \%$, and the valve was turned off. Condensate collected from the condenser contained PA in the upper layer and bio-oil in the lower layer. The raw PA obtained had a clear reddish-brown color similar to black tea. The solid residue remaining in the pyrolysis kettle was biochar. According to the law of conservation of mass, the mass difference from input and output products was determined by the product mass of non-condensable gas.

Figure 7. Schematic diagram of the pyrolysis equipment.

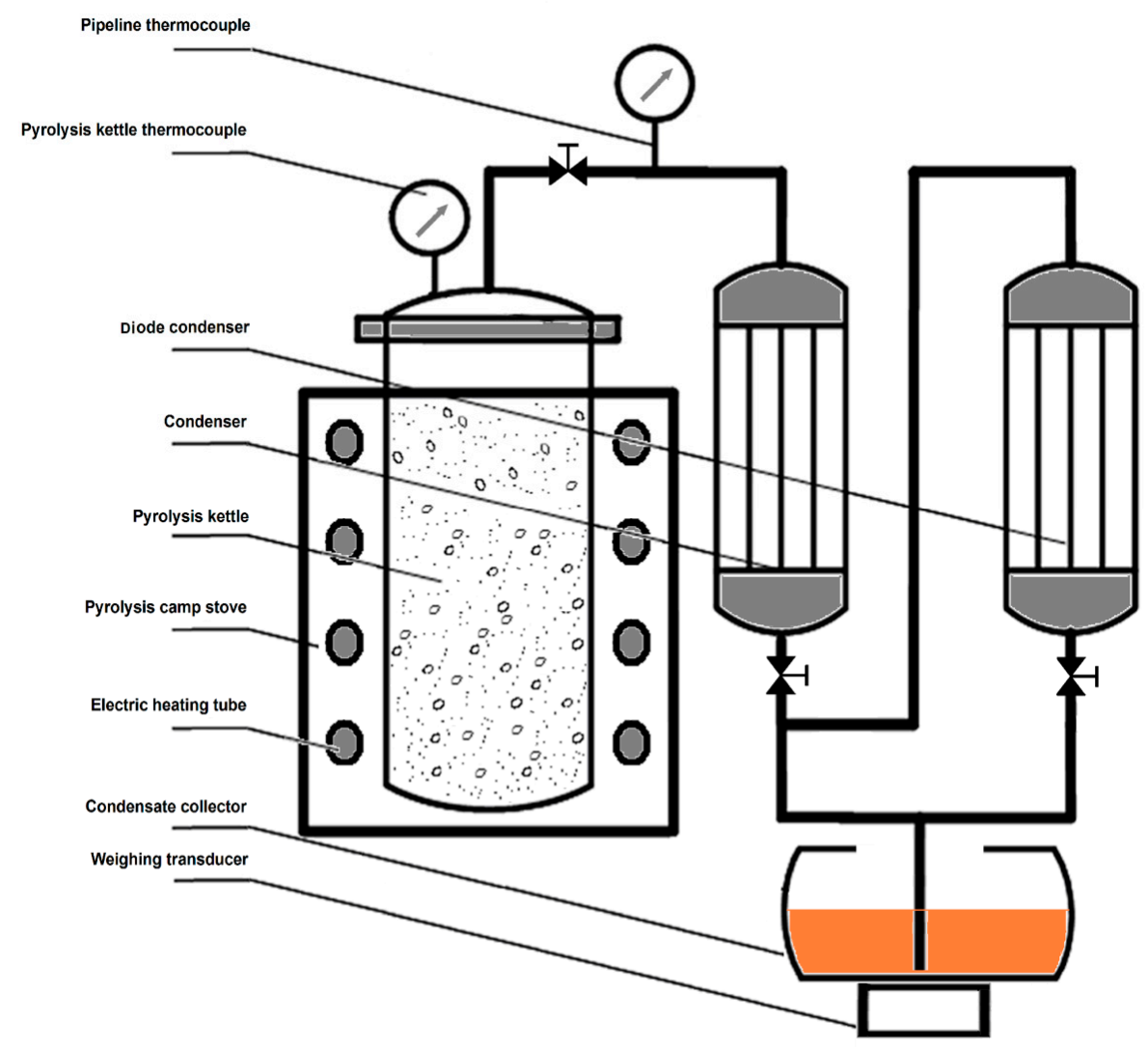

\subsubsection{Preparation Method of PA Extracts}

Three PA pyrolysis products were obtained, including PA-200 (heating power $200 \mathrm{~W}$, highest pyrolysis temperature $310^{\circ} \mathrm{C}$ ), PA-700 (heating power $700 \mathrm{~W}$, highest pyrolysis temperature $440{ }^{\circ} \mathrm{C}$ ), and PA-1200 (heating power 1,200 W, highest pyrolysis temperature $530{ }^{\circ} \mathrm{C}$ ). Each was obtained using $200 \mathrm{~g}$ of $S$. chinensis fruit. The ending of the pyrolysis process was that no more yellow gas was generated and no more liquid was collected. After pyrolysis, the PAs were dried over anhydrous 
sodium sulfate. They were then extracted at room temperature by mixing $(100 \mathrm{rpm})$ for $0.5 \mathrm{~h}$ with each of the following solvents: ethyl formate, dichloromethane, methanol, and tetrahydrofuran. The sodium sulfate was removed by filtration, and the organic extracts were used for antioxidant tests. While these solvents were selected for this study, they are not recommended for use in food and medicine industry, due to the residues of toxicity solvent. Especially formate, dichloromethane, and tetrahydrofuran, bacause the large consumption of organic solvent was not conducive to environmental protection. The volume of each organic solvent used was half the volume of PA. The ethyl formate extract phase (EFEP), dichloromethane extract phase (DMEP), methanol extract phase (MEP) and tetrahydrofuran extract phase (TFEP) were thick brown liquids and were stored at $4-8{ }^{\circ} \mathrm{C}$ in the dark.

\subsubsection{Folin Ciocalteu Assay}

A colorimetric assay based on a published procedure with slight modifications $[10,43]$ was used for estimating the total phenolic content of PA. Each sample $(1 \mathrm{~mL})$ was pipetted into a tube, and $50 \%$ Folin Ciocalteu's reagent $(1 \mathrm{~mL})$ and $10 \%$ sodium carbonate solution $(1 \mathrm{~mL})$ were added. The solutions were vortex mixed for $30 \mathrm{~s}$, and then left to stand at room temperature for $2 \mathrm{~h}$. Absorbance measurements were recorded at $765 \mathrm{~nm}$, using gallic acid to construct calibration curves. The results are reported as mean values expressed as milligrams of gallic acid equivalents per gram of sample.

\subsubsection{Ferric Reducing Antioxidant Power (FRAP)}

The reducing antioxidant capacity of PA and its extracts were examined using a modified FRAP assay [4]. The FRAP reagent was prepared from $300 \mathrm{mmol} / \mathrm{L}$ acetate buffer (pH 3.6), $20 \mathrm{mmol} / \mathrm{L}$ ferric chloride, and $10 \mathrm{mmol} / \mathrm{L}$ 2,4,6-tripyridyl-s-triazine diluted in $40 \mathrm{mmol} / \mathrm{L}$ hydrochloric acid. The three solutions were mixed in a ratio of 25:2.5:2.5 (v/v/v). The FRAP assay was performed using reagents preheated to $38{ }^{\circ} \mathrm{C}$. Before analysis, the initial absorbance of $3 \mathrm{~mL}$ of the reagent and $3 \mathrm{~mL}$ of acetate buffer used as a blank were measured at $593 \mathrm{~nm}$. The samples $(100 \mu \mathrm{L})$ were transferred into test tubes containing the reagent. The mixtures were shaken thoroughly and he absorbance values at $593 \mathrm{~nm}$ were recorded after $90 \mathrm{~min}$. A higher absorbance indicated a higher ferric reducing power. The reducing antioxidant power of the sample is expressed as Trolox equivalent (TE/g), which is the ratio between the slope of the sample's regression line and that of Trolox.

\subsubsection{DPPH Free Radical Scavenging Activity}

The DPPH radical scavenging activities of PA and its extracts were examined using the method of Lee et al. [44] and compared with those of the synthetic antioxidants BHA and BHT. Briefly, a $1.0 \mathrm{~mL}$ sample was mixed with $2.0 \mathrm{~mL}$ of a methanolic solution of DPPH $(35 \mathrm{mg} / \mathrm{L})$ in a lightproof container. The mixture was shaken $(100 \mathrm{rpm})$ and allowed to stand at room temperature for $30 \mathrm{~min}$. Then, the absorbance was measured at $517 \mathrm{~nm}$ (UV-2550 spectrophotometer, Shimadzu, Kyoto, Japan) against methanol as a blank. Lower absorbance values for the reaction mixture indicated higher free radical scavenging activity. The percentage of DPPH discoloration of the samples was calculated according to the formula:

$$
\mathrm{SC} \%=\left(\mathrm{A}_{0}-\mathrm{A}\right) / \mathrm{A}_{0} \times 100
$$


where $A_{0}$ is the absorbance of the control reaction, which contained all reagents except the test compound; and A is the absorbance of the sample. The sample concentration providing $50 \%$ inhibition (SC50) was calculated from a graph of inhibition percentage against sample concentration.

\subsubsection{GC-MS Analysis}

GC-MS analysis was carried out on an Agilent 7890A GC system (Agilent Technologies, Palo Alto, CA, USA) fitted with a DB-17MS capillary column $(30 \mathrm{~mm} \times 0.25 \mathrm{~mm}$, film thickness $0.25 \mu \mathrm{m})$ and equipped with an Agilent 7693 auto sampler, and 5975C inert XL EI/CI mass selective detector with triple-axis detector. A sample volume of $2 \mu \mathrm{L}$ was injected manually in splitless mode. The carrier gas was helium (He) at a flow rate of $1.0 \mathrm{~mL} / \mathrm{min}$. The oven temperature was set at $60{ }^{\circ} \mathrm{C}$ for the initial $5 \mathrm{~min}$, then increased to $120{ }^{\circ} \mathrm{C}$ at a rate of $10{ }^{\circ} \mathrm{C} / \mathrm{min}$ and held for $5 \mathrm{~min}$, increased to $200{ }^{\circ} \mathrm{C}$ at a rate of $10{ }^{\circ} \mathrm{C} / \mathrm{min}$ and held for $5 \mathrm{~min}$, and then increased to $280^{\circ} \mathrm{C}$ at a rate of $10{ }^{\circ} \mathrm{C} / \mathrm{min}$ and held for $15 \mathrm{~min}$. The injector and detector temperatures were $280{ }^{\circ} \mathrm{C}$ and $230{ }^{\circ} \mathrm{C}$, respectively. The pressure and flow rate of the injector were $15.0 \mathrm{psi}$ and $25.0 \mathrm{~mL} / \mathrm{min}$, respectively. The $\mathrm{MS}$ was operated at $70 \mathrm{eV}$, and the scan range (TIC) was 50-500 $\mathrm{m} / \mathrm{z}$.

\section{Conclusions}

The pyrolysis process and products of $S$. chinensis fruit were studied. The yield of PA was higher with a lower pyrolysis heating power than with a higher pyrolysis heating power. Based on the total phenolic contents of the PA extracts, PA-200 was selected to test for antioxidant activities, including free radical scavenging activity and ferric reducing power. MEP and DMEP of PA-200 showed superior characteristics compared to the other extracts. Phenols and polyenes were the major components in MEP and DMEP, followed by ketones and furan derivatives. The results indicated that phenols were the functional components from $S$. chinensis fruit responsible for the reduction of oxidants and scavenging of free radicals in PA. The organic solvents in the PA extracts were vacuum evaporated, and then dissolved in ethanol, used in food, medicine, cosmetics and pesticides industry, respectively. Moreover, the further analysis of PA extracts, such as toxicity tests are necessary.

\section{Acknowledgments}

The authors thank the Fundamental Research Funds for the Central Universities (Grant No. 2572014EY01) and Hei Long Jiang postdoctoral foundation for financial support.

\section{Author Contributions}

LY and YZ conceived and designed the experiments; CM and WL Performed the experiments and analyzed the data; YZ and JL contributed reagents, materials, and analysis tools; CM wrote the paper. All authors read and approved the final manuscript.

\section{Conflicts of Interest}

The authors declare no conflict of interest. 


\section{References}

1. Minkova, V.; Marinov, S.P.; Zanzi, R.; Bjornbom, E.; Budinova, T.; Stefanova, M.; Lakov, L. Thermochemical treatment of biomass in a flow of steam or in a mixture of steam and carbon dioxide. Fuel Process. Technol. 2000, 62, 45-52.

2. Schröder, E. Experiments on the pyrolysis of large beechwood particles in fixed beds. J. Anal. Appl. Pyrolysis 2004, 71, 669-694.

3. Guerrero, M.; Ruiz, M.P.; Alzueta, M.U.; Bilbao, R.; Millera, A. Pyrolysis of eucalyptus at different heating rates: Studies of char characterization and oxidative reactivity. J. Anal. Appl. Pyrolysis 2005, 74, 307-314.

4. Guillén, M.D.; Manzanos, M.J. Study of the volatile composition of an aqueous oak smoke preparation. Food Chem. 2002, 79, 283-292.

5. Bubonja-Sonje, M.; Giacometti, J.; Abram, M. Antioxidant and antilisterial activity of olive oil, cocoa and rosemary extract polyphenols. Food Chem. 2011, 127, 1821-1827.

6. Mohan, D.; Pittman, C.U.; Steele, P.H. Pyrolysis of wood/biomass for bio-oil: A critical review. Energy Fuel 2006, 20, 848-889.

7. Nakai, T.; Kartel, S.N.; Hata, T.; Imamura, Y. Chemical characterization of pyrolysis liquids of wood-based composites and evaluation of their bioefficiency. Build. Environ. 2007, 42, 1236-1241.

8. Ratanapisit, J.; Apiraksakul, S.; Rerngnarong, A.; Chungsiriporn, J.; Bunyakarn, C. Preliminary evaluation of production and characterization of wood vinegar from rubber wood. Songklanakarin J. Sci. Technol. 2009, 31, 343-349.

9. Chang, Y.; Zhao, S.; Ni, W.; Wo, N. Research of the antioxidative properties of bamboo vinegar. J. East China Univ. Sci. Technol. (Nat. Sci. Ed.) 2004, 30, 640-643.

10. Loo, A.Y.; Jain, K.; Darah, I. Antioxidant and radical scavenging activities of the pyroligneous acid from a mangrove plant, Rhizophora apiculata. Food Chem. 2007, 107, 300-307.

11. Wei, Q.; Ma, X.; Zhao, Z.; Zhang, S.; Liu, S. Antioxidant activities and chemical profiles of pyroligneous acids from walnut shell. J. Anal. Appl. Pyrolysis 2010, 88, 149-154.

12. Cai, K.; He, Y. Antioxidant activities of the pyroligneous acid in living Caenorhabditis elegans. Adv. Mater. Res. 2011, 236-238, 2564-2569.

13. Amarowicz, R.; Estrella, I.; Hernández, T.; Robredo, S.; Troszyńska, A.; Kosińska, A.; Pegg, R.B. Free radical-scavenging capacity, antioxidant activity, and phenolic composition of green lentil (Lens culinaris). Food Chem. 2010, 121, 705-711.

14. Lu, Q.; Liu, W.; Yang, L.; Zu, Y.; Zu, B.; Zhu, M.; Zhang, Y.; Zhang, X.; Zhang, R.; Sun, Z.; et al. Investigation of the effects of different organosolv pulping methods on antioxidant capacity and extraction efficiency of lignin. Food Chem. 2012, 131, 313-317.

15. Yang, L.; Huang, J.; Zu, Y.; Ma, C.; Wang, H.; Sun, X.; Sun, Z. Preparation and radical scavenging activities of polymeric procyanidins nanoparticles by a supercritical antisolvent (SAS) process. Food Chem. 2011, 128, 1152-1159.

16. Wang, H.; Zu, G.; Yang, L.; Zu, Y.; Wang, H.; Zhang, Z.; Zhang, Y.; Zhang, L.; Wang, H. Effects of heat and ultraviolet radiation on the stability of pine nut oil supplemented with carnosic acid. J. Agric. Food Chem. 2011, 59, 13018-13025. 
17. Ahmeda, A.; Hossain, M.A.; Ismail, Z. Antioxidant properties of the isolated flavonoids from the medicinal plant Phyllanthus niruri. Asian J. Food Agro-Ind. 2009, 2, 373-381.

18. Valentao, P.; Fernandes, E.; Carvalho, F.; Andrade, P.B.; Seabra, R.M.; Bastos, M.L. Antioxidative properties of cardoon (Cynara cardunculus L.) infusion against superoxide radical hydroxyl radical, and hypochlorous acid. J. Agric. Food Chem. 2002, 50, 4989-4993.

19. Ma, C.; Song, K.; Yu, J.; Yang, L.; Zhao, C.; Wang, W.; Zu, G.; Zu, Y. Pyrolysis process and antioxidant activity of pyroligneous acid from Rosmarinus officinalis leaves. J. Anal. Appl. Pyrolysis 2013, 104, 38-47.

20. Pharmacopoeia of the People's Republic of China; Peoples Medicinal Publishing House: Beijing, China, 2010; Volume I, pp. 61-62.

21. Park, J.Y.; Shin, H.K.; Lee, Y.J.; Choi, Y.W.; Bae, S.S.; Kim, C.D. The mechanism of vasorelaxation induced by Schisandra chinensis extract in rat thoracic aorta. J. Ethnopharmacol. 2009, 121, 69-73.

22. Chang, G.T.; Kang, S.K.; Kim, J.H.; Chung, K.H.; Chang, Y.C.; Kim, C.H. Inhibitory effect of the Korean herbal medicine, Dae-Jo-Whan, on platelet-activating factor-induced platelet aggregation. J. Ethnopharmacol. 2005, 102, 430-439.

23. Chen, C.G. Basic Theory of Traditional Chinese Medicine; Shanghai of TCM Press: Shanghai, China, 2002.

24. Deng, X.; Chen, X.; Yin, R.; Shen, Z.; Qiao, L.; Bi, K. Determination of deoxyschizandrin in rat plasma by LC-MS. J. Pharma. Biomed. Anal. 2008, 46, 121-126.

25. Fu, M.; Sun, Z.; Zong, M.; He, X.; Zuo, H.; Xie, Z. Deoxyschisandrin modulates synchronized $\mathrm{Ca}^{2+}$ oscillations and spontaneous synaptic transmission of cultured hippocampal neurons. Acta Pharmacol. 2008, 29, 891-898.

26. Guo, L.Y.; Hung, T.M.; Bae, K.H.; Shin, E.M.; Zhou, H.Y.; Hong, Y.N.; Kang, S.S.; Kim, H.P.; Kim, Y.S. Anti-inflammatory effects of schisandrin isolated from the fruit of Schisandra chinensis Baill. Eur. J. Pharmacol. 2008, 591, 293-299.

27. Peng, J.; Fan, G.; Qu, L.; Zhou, X.; Wu, Y. Application of preparative high-speed counter-current chromatography for isolation and separation of schizandrin and gomisin A from Schisandra chinensis. J. Chromatogr. A 2005, 1082, 203-207.

28. Zhao, J.; Meng, Z.; Li, G.; Wang, Y. Study on processing of coagulation Schizandra chinensis yogurt. Food Sci. Technol. 2009, 34, 49-51.

29. Liang, X.; Wen, J. Progress on Schisandra chinensis (Turcz.) Baill. Health Food Drug 2009, 11, $70-73$.

30. Guan, X.; Huo, F.; Yu, W.; Hu, Y. The exploitation for the extractive of fructus schisandrae chinensis in natural sapid substance. China Food Addit. 2007, 18, 110-113.

31. Sun, C.; Wang, S.; Ding, X.; Li. Z. Application and development prospects of the fruits of Schisandra chinensis in food industry. Food Mach. 2003, 19, 9-10.

32. Ma, C.; Yang, L.; Zu, Y.; Liu, T. Optimization of conditions of solvent-free microwave extraction and study on antioxidant capacity of essential oil from Schisandra chinensis (Turcz.) Baill. Food Chem. 2012, 4, 2532-2539.

33. Chen, Y.; Tang, J.; Wang, X.; Sun, F.; Liang, S. An immunostimulatory polysaccharide (SCP-IIa) from the fruit of Schisandra chinensis (Turcz.) Baill. Int. J. Boil. Macromol. 2012, 50, 844-848. 
34. Ma, C.; Yang, L.; Yang, F.; Wang, W.; Zhao, C.; Zu, Y. Content and colour stability of anthocyanins isolated from Schisandra chinensis (Turcz.) Baill fruits. Int. J. Mol. Sci. 2012, 13, 14294-14310.

35. Hancke, J.L.; Burgos, R.A.; Ahumada, F. Review Schisandra chinensis (Turcz.) Baill. Fitoterapia 1999, 70, 451-471.

36. Ma, C.H.; Liu, T.T.; Yang, L.; Zu, Y.G.; Yang, F.J.; Zhao, C.J.; Zhang, L.; Zhang, Z.H. Preparation of high purity biphenyl cyclooctene lignans from Schisandra extract by ion exchange resin catalytic transformation combined with macroporous resin separation. J. Chromatogr. B 2011, 879, 3444-3451.

37. Jerez, M.; Pinelo, M.; Sineiro, J.; Nuñez, M.J. Influence of extraction conditions on phenolic yields from pine bark: Assessment of procyanidins polymerization degree by thiolysis. Food Chem. 2004, 94, 406-414.

38. Siddhuraju, P. Antioxidant activity of polyphenolic compounds extracted from defatted raw and dry heated Tamarindus indica seed coat. LWT-Food Sci. Technol. 2007, 40, 982-990.

39. Soares, J.R.; Dins, T.C.P.; Cunha, A.P.; Ameida, L.M. Antioxidant activity of some extracts of Thymus zygis. Free Radic. Res. 1997, 26, 469-478.

40. Mansaray, K.G.; Ghaly, A.E. Physical and thermochemical properties of rice husk. Energy Sources 1997, 19, 989-1004.

41. Baker, R.R. Kinetic parameters from the nonisothermal decomposition of a multicomponent solid. Thermochim. Acta 1978, 23, 201-212.

42. Bradbury, A.G.W.; Sakai, Y.; Shafizadeh, F. A kinetic model for pyrolysis of cellulose. J. Appl. Polym. Sci. 1979, 23, 3271-3280.

43. Liu, X.; Jia, J.; Yang, L.; Yang, F.; Ge, H.; Zhao, C.; Zhang, L.; Zu, Y. Evaluation of antioxidant activities of aqueous extracts and fractionation from different parts of Elsholtzia ciliate. Molecules 2012, 17, 5430-5441.

44. Zu, S.; Yang, L.; Huang, J.; Ma, C.; Wang, W.; Zhao, C.; Zu. Y. Micronization of taxifolin by supercritical antisolvent process and evaluation of radical scavenging activity. Int. J. Mol. Sci. 2012, 13, 8869-8881.

Sample Availability: Samples of S. chinensis fruits are available from the authors.

(C) 2014 by the authors; licensee MDPI, Basel, Switzerland. This article is an open access article distributed under the terms and conditions of the Creative Commons Attribution license (http://creativecommons.org/licenses/by/4.0/). 